\title{
Comparison between the Needle and Roller Electrospinning of Polyvinylbutyral
}

\author{
F. Yener and O. Jirsak \\ Department of Nonwovens, Faculty of Textile Engineering, Technical University of Liberec, Studentska 2, 46117 Liberec, Czech Republic \\ Correspondence should be addressed to F. Yener, yenertex@hotmail.com
}

Received 13 December 2011; Revised 30 January 2012; Accepted 16 February 2012

Academic Editor: Tong Lin

Copyright ( $) 2012$ F. Yener and O. Jirsak. This is an open access article distributed under the Creative Commons Attribution License, which permits unrestricted use, distribution, and reproduction in any medium, provided the original work is properly cited.

The effect of the concentration of polyvinylbutyral solution on the process throughput and fibre properties was studied in needle and roller electrospinning. Whereas the polymer throughput is an optional independent parameter in needle electrospinning, it is a dependent parameter that is affected by both the material and process parameters in roller electrospinning. Polymer throughput increases considerably with an increasing concentration of polymer solutions in roller electrospinning. The properties of the nanofibers and the quality of the nanofiber layers were also studied. Fibre diameters increase with an increasing concentration in both techniques. Fibre diameters produced by needle electrospinning are smaller than those produced by roller electrospinning. The distribution of fibre diameters is rather narrow and not significantly dependent on the concentration of solutions in either technique.

\section{Introduction}

In recent years, polymer nanofibres have gained considerable attention as promising materials with many possible areas of application, due to their unique properties such as a high specific surface area, small pore diameters, high surface to weight ratio, good barrier characteristics against microorganisms and fine particles, high surface energy, good strength per unit weight, and covering effects [1-11]. There are several methods to produce fibres at a nanoscale [12-16]. Electrospinning is one of these methods. In the electrospinning method, a polymer solution is forced through a hollow needle, and a high voltage is applied to the polymer solution coming out at the needle tip (Figure 1).

Another method for producing nanofibres was developed by Jirsak et al. [17]. This method is called roller electrospinning, and known under the name Nanospider (Figure 2). Roller electrospinning is a viable route for the production of exceptionally continuous and uniform polymer nanofibres.

Viscosity, concentration, surface tension, molecular weight, conductivity, and the dielectric properties of the polymer solution are classified as material parameters for both electrospinning methods.
Process parameters include voltage, feed rate of the polymer solution, distance between collector and needle tip, temperature of solution, and the temperature and humidity inside the spinner. Each parameter plays a role in the outcome of the electrospinning process [18-23].

Polymer concentration plays a major role in the electrospinning process. Under the same electrospinning conditions, an increasing polymer concentration usually increases the diameter of the electrospun fibres. However, Deitzel et al. found that there is often a nonlinear relationship between the solution concentration and fibre diameter [20]. The reason for this nonlinear relationship can be attributed to the nonlinear relationship between the polymer concentration and solution viscosity [21].

Polyvinylbutyral (PVB) polymers have been extensively used for many applications, since PVB is a low-cost alternative that offers strong binding ability, flexibility, optical clarity, and adhesion to many surfaces. In spite of the high popularity of PVB polymers, there is scarce information about PVB nanofibres. In this work, the effects of concentration of the polyvinylbutyral solution on the process throughput and fibre properties were studied. 


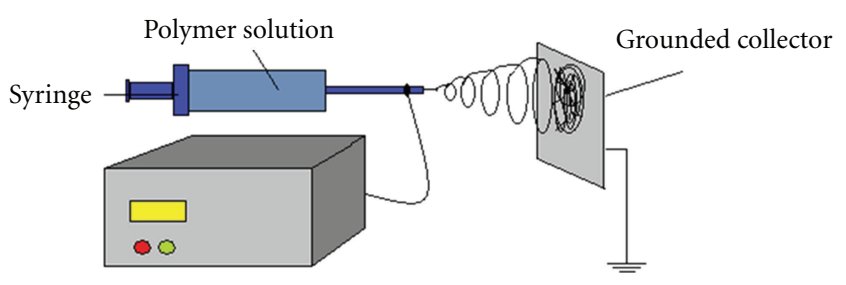

High-voltage supplier

Figure 1: Diagram of needle electrospinning set-up.

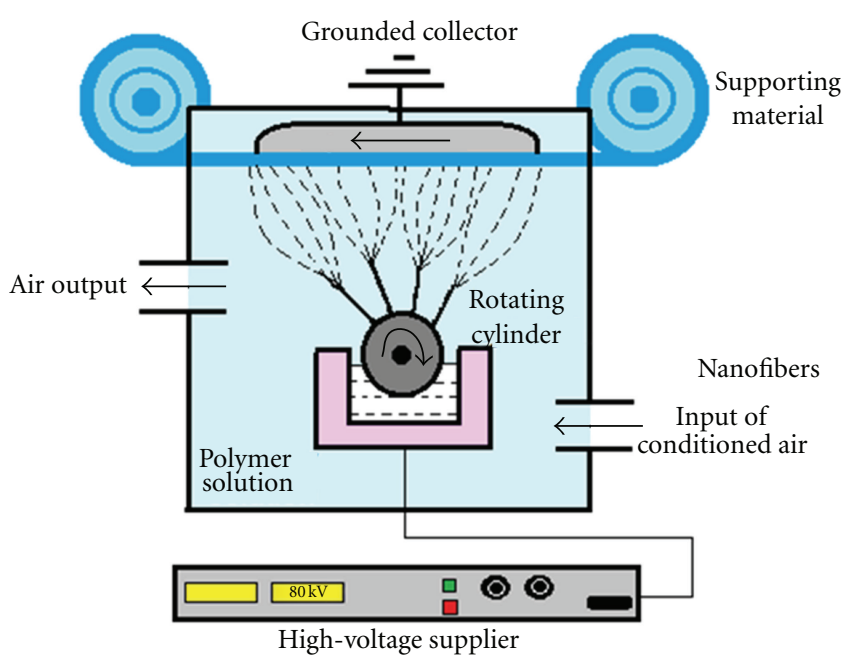

FIgURE 2: Diagram of roller electrospinning set-up.

\section{Experiment}

2.1. Materials and Methods. PVB60H Mowital with 60,000 g/ mol was obtained from Kuraray, Japan. Isopropanol of p.a. quality was used as the solvent.

The experimental set-up for needle electrospinning consists of a $50 \mathrm{~mL}$ syringe and a stainless steel needle that is positioned horizontally as shown in Figure 1.

The roller electrospinning device contains a roller spinning electrode partially immersed in the tank with the polymer solution. A grounded collector electrode is placed at the top of the spinner (Figure 2). A nonwoven backing material moves along the collector electrode which makes the production of the nanofibre layer a continuous process. Many Taylor cones are simultaneously formed on the surface of the rotating spinning electrode, which makes the technology highly productive. Spinning conditions are shown in Table 1.

Solutions of PVB in isopropanol with concentrations of $6,7,8,9$, and $10 \mathrm{wt} . \%$ were prepared.

In needle electrospinning, voltages of 20,25 , and $30 \mathrm{kV}$ were applied to the solution, and the nanofibres were collected on the aluminium foil collector placed at a distance of $200 \mathrm{~mm}$ from the tip of the needle. The flow rate of the polymer solution was $0.5 \mathrm{~mL} / \mathrm{h}$, the temperature was $22^{\circ} \mathrm{C}$, and relative humidity was $69 \%$.

Conductivity (conductivity meter), surface tension (Krüss), and viscosity (Haake RotoViscol at $23^{\circ} \mathrm{C}$ ) of the polymer solutions were measured. Images of the fibres were taken by SEM (Phenom FEI), and the diameters of the fibres were calculated using the Lucia $32 \mathrm{G}$ programme.

The polymer throughput of the roller electrospinning process was calculated from the area weight and width of the nanofibre layer and from the velocity of the backing material, using

$$
P=G * W * V_{\text {fabric }} * \frac{1}{L r}(\mathrm{~g} / \mathrm{min} / \mathrm{m})
$$

where $P$ is polymer throughput $(\mathrm{g} / \mathrm{min} / \mathrm{m}), G$ represents nanofibre layer area weight $\left(\mathrm{g} / \mathrm{m}^{2}\right), W$ denotes width of nanofibre layer $(\mathrm{m}), V_{\text {fabric }}$ is backing fabric take-up speed ( $\mathrm{m} / \mathrm{min})$, and $\mathrm{Lr}$ denotes length of roller spinning electrode (m).

\section{Results and Discussion}

3.1. Needle Electrospinning. The basic properties of the PVB solutions are shown in Figure 3 and Table 2. Viscosity of the solutions increases with increasing concentration.

SEM microphotographs of the nanofibres produced by needle spinning are shown in Figure 4, while those of the nanofibres produced by roller electrospinning are shown in Figure 6.

The dependencies of the fibre diameters produced by both techniques on the viscosity of solutions are shown in Figures 5 and 7. In Figure 7 the dependence of the polymer 
TABLE 1: Spinning conditions of roller electrospinning.

\begin{tabular}{lcccc}
\hline Applied voltage $(\mathrm{kV})$ & $\begin{array}{c}\text { Distance between } \\
\text { roller and collector } \\
(\mathrm{cm})\end{array}$ & Relative humidity $(\%)$ & Temperature $\left({ }^{\circ} \mathrm{C}\right)$ & $\begin{array}{c}\text { Fabric speed } \\
(\mathrm{cm} / \mathrm{min})\end{array}$ \\
\hline 80 & 18 & 44 & 24 & $\begin{array}{c}\text { Roller speed } \\
(\mathrm{rpm}) / \mathrm{length}(\mathrm{cm})\end{array}$ \\
\hline
\end{tabular}

TABLE 2: Conductivity and surface tension of PVB polymer solutions at different concentrations.

\begin{tabular}{lccccc}
\hline & $6 \%$ & $7 \%$ & $8 \%$ & $9 \%$ & \\
\hline Surface tension $(\mathrm{mN} / \mathrm{m})$ & 23.1 & 23 & 22.3 & 22.4 & 22.3 \\
Conductivity $\left(\mu \mathrm{S} \cdot \mathrm{cm}^{-1}\right)$ & 1.92 & 2.32 & 2.4 & 2.1 & 2.22 \\
\hline
\end{tabular}

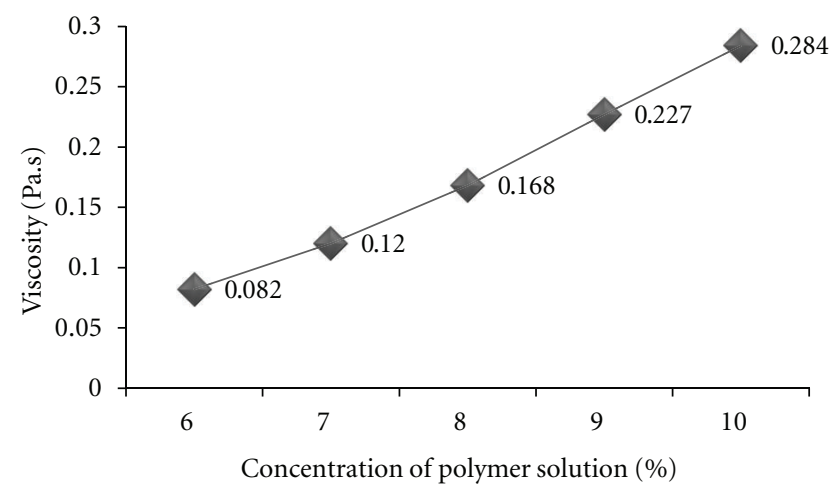

FIGURE 3: Dependence of viscosity of PVB solutions in isopropanol on concentration.

throughput on the concentration of the solution is also shown.

Distribution of fibre diameters was characterised using the fibre uniformity coefficient $C_{\mathrm{FU}}$. This was defined similarly to the characterisation of the molecular weight distribution in macromolecular chemistry:

$$
C_{\mathrm{FU}}=\frac{A_{w}}{A_{n}},
$$

where

$$
\begin{gathered}
A n=\frac{\sum n_{i} d_{i}}{\sum n_{i}}, \\
A w=\frac{\sum n_{i} d_{i}^{2}}{\sum n_{i} d_{i}},
\end{gathered}
$$

where $d_{i}$ is fibre diameter, and $n_{i}$ denotes the number of fibres with diameter $d_{i}$.

Monodisperse systems show $C_{\mathrm{FU}}$ is equal to one. The bigger the $C_{\mathrm{FU}}$, the broader the distribution of $\mathbf{d}$.

Dependence of the fibre uniformity coefficient $C_{\mathrm{FU}}$ on the concentration of the PVB solutions is shown in Figure 8.

The polymer solutions show almost identical values of surface tension and electrical conductivity (Table 2). Therefore, the studied properties of the nanofibres and throughput of roller electrospinning only depend on the concentration of the solutions and on the corresponding viscosities, respectively (Figure 3 ).

Quality and diameters of nanofibres generally depend on the concentration of solutions. In needle electrospinning, a low concentration leads to nanofibres with beads (Figure 4(a)). This effect was described in many papers and is related to the low relation of viscosity to surface tension. High viscosity, on the other hand, (Figure 4(e)) leads to greater fibre diameters due to the limited deformability of the polymer jet and/or the shorter time needed for the solidification of the more concentrated solution. Concentrations of 7-9 wt.\% seem to be optimum in needle electrospinning. In roller electrospinning, SEM microphotographs (Figure 6) reveal a different character of the fibres. At low concentrations of the solution the photograph shows nonfibrous formations (Figures 6(a) and 6(b)) instead of beads as in Figure 4(a). At high concentrations (Figure 6(e)), the fibres seem to have great diameters. Nevertheless, a closer look reveals that the fibre elements consist of several fibres; in other words the elements are bundles of single fibres. The formation of such bundles is connected with the high throughput of the process when the concentration of the solution is high (Figure 7). In this case, there are too many nanofibres in the space between the spinning and collector electrodes which leads to the entanglement and sticking of single fibres. To produce high-quality nanofibres, the concentration of the solution must be kept at the values of $8-9 \mathrm{wt} . \%$ in the case of roller electrospinning.

Generally, nanofibres produced by roller electrospinning have greater diameters when compared with those produced using a needle (Figure 5). Optimisation of the roller production parameters is more demanding, and the production process is more sensitive to the surrounding conditions. On the other hand, the polymer throughput of roller electrospinning is much greater.

Diameters of fibres produced from the solutions of PVB in isopropanol are rather larger. In the case of roller electrospinning, these correspond to microfibers rather than to nanofibres. Diameters of PVB nanofibres produced from other solvents are considerably smaller. Isopropanol was used in this work because the differences in fibre diameters were more distinctive. 


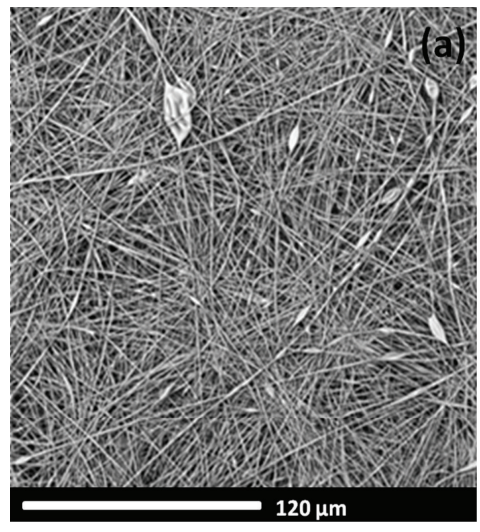

(a)

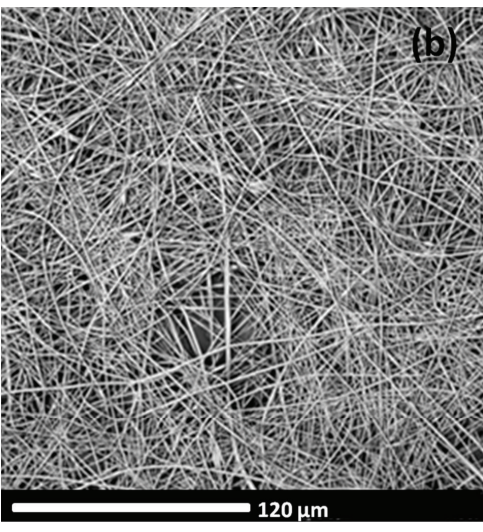

(b)

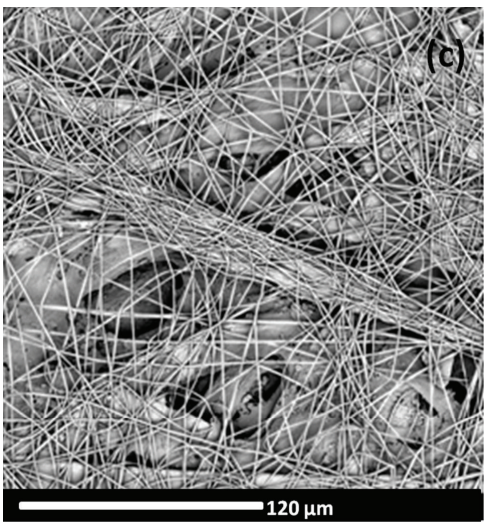

(c)

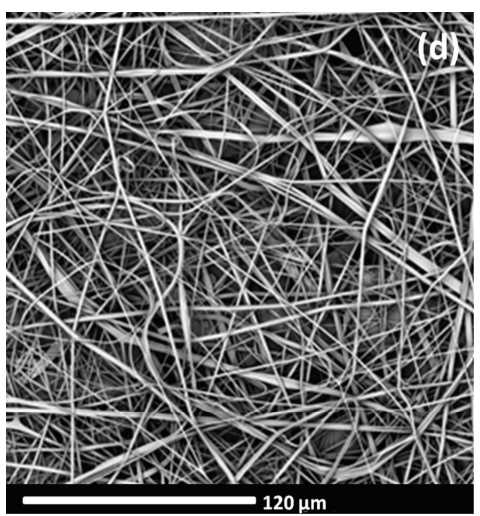

(d)

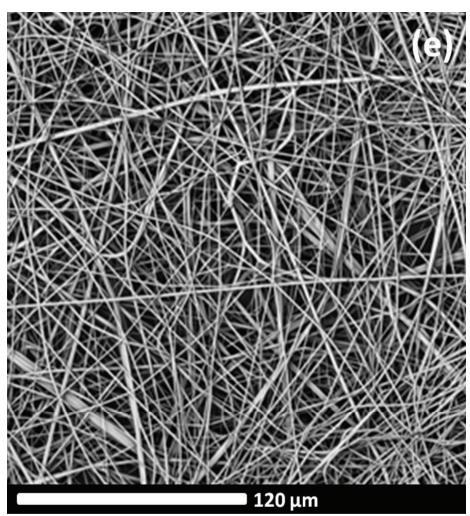

(e)

FIGURE 4: SEM microphotographs of nanofibre layers produced by needle electrospinning of PVB solutions 6 (a), 7 (b), 8 (c), 9 (d), and 10 (e) wt.\%.

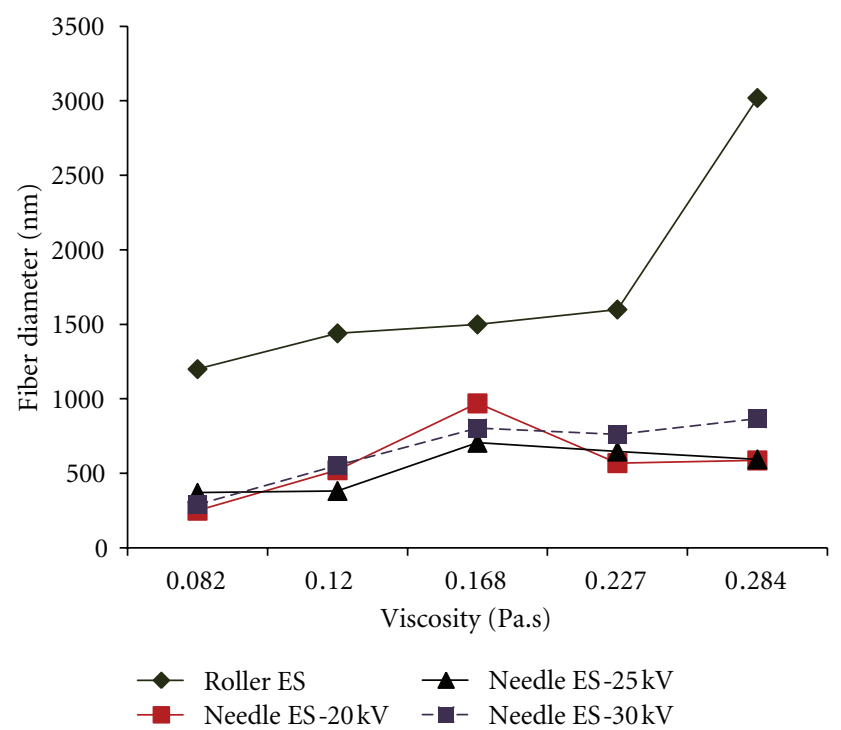

FIGURE 5: Relationship between viscosity and fibre diameter on both roller and needle electrospinning systems. 


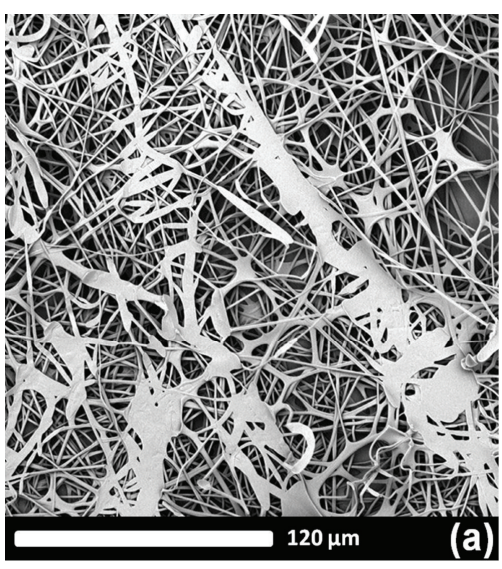

(a)

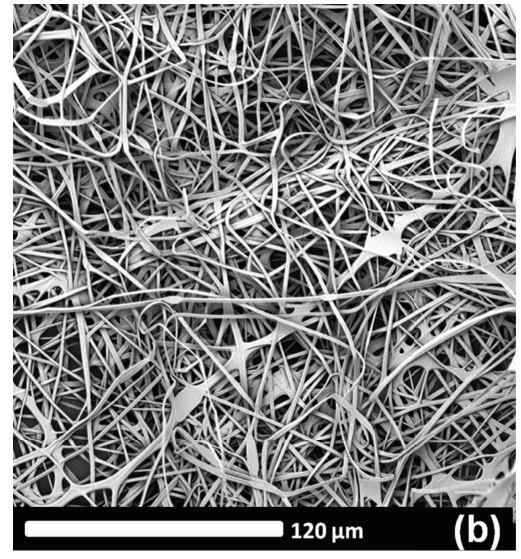

(b)

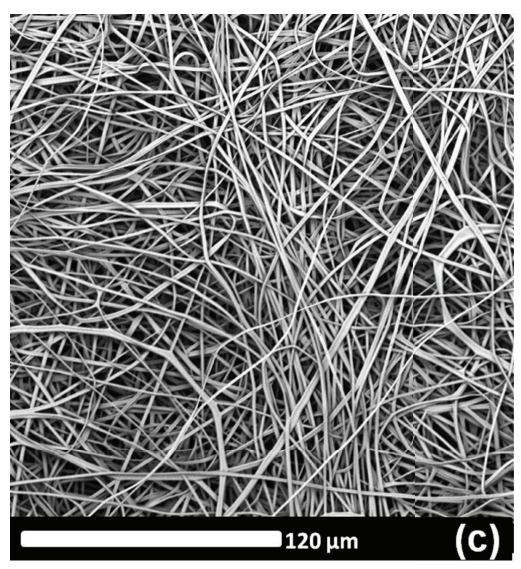

(c)

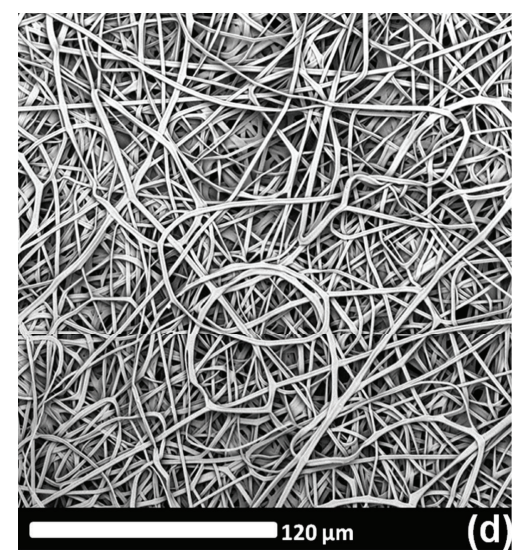

(d)

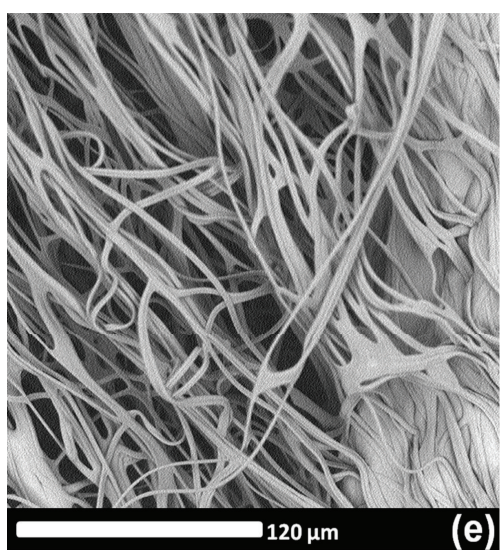

(e)

FIGURE 6: SEM microphotographs of nanofibre layers produced by roller electrospinning of PVB solutions 6 (a), 7 (b), 8 (c), 9 (d), and 10 (e) wt.\%.

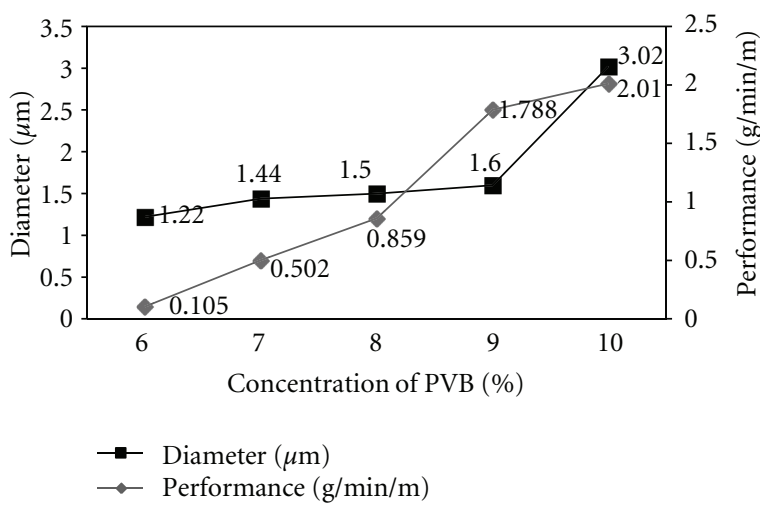

Figure 7: Dependence of fabric throughput and fibre diameter on concentration and fibre diameter of PVB nanofibre on roller electrospinning.

The increase in polymer throughput with concentration of polymer solution is known from previous work [22]. This is connected with a higher degree of entanglement of macromolecules and the resulting higher breaking strength of jets. This leads to a longer life of the jets and subsequently to a greater number of Taylor cones on the surface of the spinning electrode. Fibre diameters show a rather narrow distribution in both spinning techniques (Figure 8), which does not depend on any process parameters.

\section{Conclusions}

The experiments described in this paper were focused on the effect of concentration of polymer solutions on both needle and roller electrospinning techniques. An increase in polymer concentration leads to a higher throughput in roller electrospinning and to greater fibre diameters in both techniques. Needle electrospinning results in nanofibres of smaller diameters. On the other hand, roller electrospinning shows a considerably greater throughput. The distribution of fibre diameters was rather narrow in all the experiments. Concentrations of $8-9$ wt.\% seem to be optimal at the used polymer dissolved in isopropanol. Nevertheless, isopropanol 


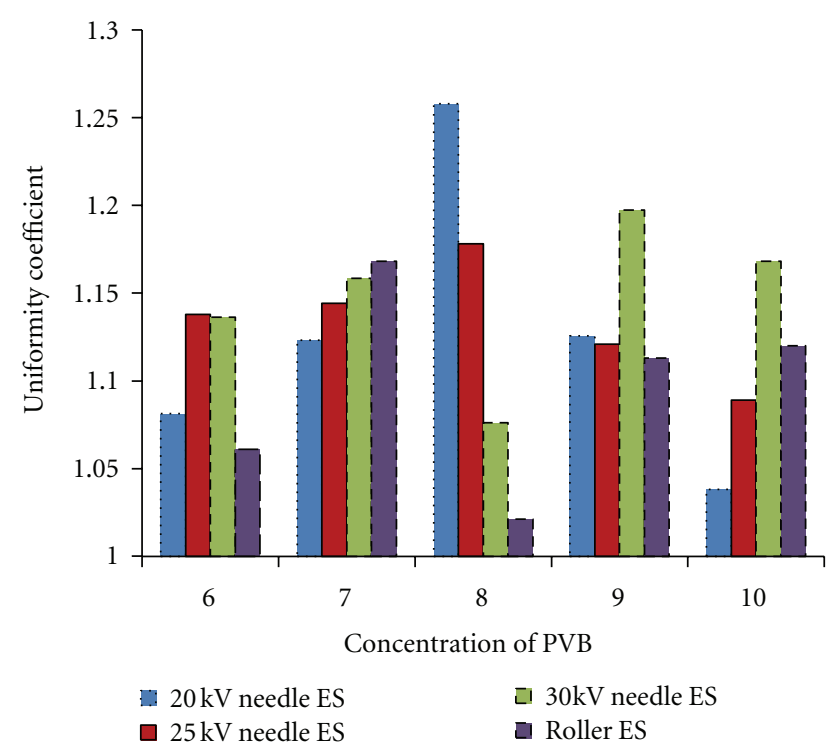

FIGURE 8: Fibre uniformity coefficient.

is not a suitable solvent as the resulting fibre diameters are rather large.

\section{Acknowledgments}

The authors are thankful to the Ministry of Education, Youth and Sports of the Czech Republic (Student's Grant Competition TUL in Specific University Research in 2012, Project no. 4866) for its financial support. Speacial thanks are due to all technicians at the Technical University of Liberec, Kahramanmaras Sutcu Imam University and to Dr. Funda Cengiz, Dr. Dao Anh Tuan, and Mr. Baturalp Yalçınkaya for their support.

\section{References}

[1] T. Lin, H. Wang, and X. Wang, "Self-crimping bicomponent nanofibers electrospun from polyacrylonitrile and elastomeric polyurethane," Advanced Materials, vol. 17, no. 22, pp. 26992703, 2005.

[2] D. H. L. Bail, W. Schneider, K. Khalighi, and H. Seboldt, "Temporary wound covering with a silicon sheet for the soft tissue defect following open fasciotomy," The Journal of Cardiovascular Surgery, vol. 39, no. 5, pp. 587-591, 1998.

[3] R. M. Nerem and A. Sambanis, "Tissue engineering: from biology to biological substitutes," Tissue Engineering, vol. 1, no. 1, pp. 3-13, 1995.

[4] X. Zong, K. Kim, D. Fang, S. Ran, B. S. Hsiao, and B. $\mathrm{Chu}$, "Structure and process relationship of electrospun bioabsorbable nanofiber membranes," Polymer, vol. 43, no. 16, pp. 4403-4412, 2002.

[5] P. Taepaiboon, U. Rungsardthong, and P. Supaphol, "Drugloaded electrospun mats of poly(vinyl alcohol) fibres and their release characteristics of four model drugs," Nanotechnology, vol. 17, no. 9, pp. 2317-2329, 2006.

[6] K. Kosmider and J. Scott, "Polymeric nanofibre exhibit an enhanced air filtration performance," Filtration and Separation, vol. 39, no. 6, pp. 20-22, 2002.
[7] K. H. Hong, "Preparation and properties of electrospun poly (vinyl alcohol)/silver fiber web as wound dressings," Polymer Engineering and Science, vol. 47, no. 1, pp. 43-49, 2007.

[8] J. S. Choi, K. W. Leong, and H. S. Yoo, "In vivo wound healing of diabetic ulcers using electrospun nanofibers immobilized with human epidermal growth factor (EGF)," Biomaterials, vol. 29, no. 5, pp. 587-596, 2008.

[9] A. C. Patel, S. Li, C. Wang, W. Zhang, and Y. Wei, "Electrospinning of porous silica nanofibers containing silver nanoparticles for catalytic applications," Chemistry of Materials, vol. 19, no. 6, pp. 1231-1238, 2007.

[10] X. M. Mo, C. Y. Xu, M. Kotaki, and S. Ramakrishna, "Electrospun P(LLA-CL) nanofiber: a biomimetic extracellular matrix for smooth muscle cell and endothelial cell proliferation," Biomaterials, vol. 25, no. 10, pp. 1883-1890, 2004.

[11] J. J. Stankus, L. Soletti, K. Fujimoto, Y. Hong, D. A. Vorp, and W. R. Wagner, "Fabrication of cell microintegrated blood vessel constructs through electrohydrodynamic atomization," Biomaterials, vol. 28, no. 17, pp. 2738-2746, 2007.

[12] A. Formhals, "Process and Apparatus for Preparing Artificial Threads," US Patent 1,975,504, 1934.

[13] T. Ondarçuhu and C. Joachim, "Drawing a single nanofibre over hundreds of microns," Europhysics Letters, vol. 42, no. 2, pp. 215-220, 1998.

[14] P. X. Ma and R. Zhang, "Synthetic nano-scale fibrous extracellular matrix," Journal of Biomedical Materials Research, vol. 46, no. 1, pp. 60-72, 1999.

[15] J. D. Hartgerink, E. Beniash, and S. I. Stupp, "Self-assembly and mineralization of peptide-amphiphile nanofibers," Science, vol. 294, no. 5547, pp. 1684-1688, 2001.

[16] J. J. Feng, "The stretching of an electrified non-Newtonian jet: a model for electrospinning," Physics of Fluids, vol. 14, no. 11, pp. 3912-3926, 2002.

[17] O. Jirsak, F. Sanetrnik, D. Lukas, V. Kotek, L. Martinova, and J. Chaloupek, "A method of nanofibres production from a polymer solution using electrostatic spinning and a device for carrying out the method," European Patent: EP 1673 493, 2004.

[18] F. Cengiz, T. A. Dao, and O. Jirsak, "Influence of solution properties on the roller electrospinning of poly(vinyl alcohol)," Polymer Engineering and Science, vol. 50, no. 5, pp. 936-943, 2010.

[19] F. Cengiz, O. Jirsak, and M. Dayık, "An investigation the effects of ambient humidity on the roller electrospinning of nanofiber production," Electronic Journal of Textile Technologies, vol. 3, pp. 24-32, 2009.

[20] J. M. Deitzel, J. Kleinmeyer, D. Harris, and N. C. Beck Tan, "The effect of processing variables on the morphology of electrospun nanofibers and textiles," Polymer, vol. 42, no. 1, pp. 261-272, 2001.

[21] T. Lin and X. G. Wang, Controlling the Morphologies of Electrospun Nanofibres, CRC Press, 2007, Edited by P. J. Brown and K. Stevens.

[22] F. Cengiz and O. Jirsak, "The effect of salt on the roller electrospinning of polyurethane nanofibers," Fibers and Polymers, vol. 10, no. 2, pp. 177-184, 2009.

[23] J. Doshi and D. H. Reneker, "Electrospinning process and applications of electrospun fibers," Journal of Electrostatics, vol. 35, no. 2-3, pp. 151-160, 1995. 

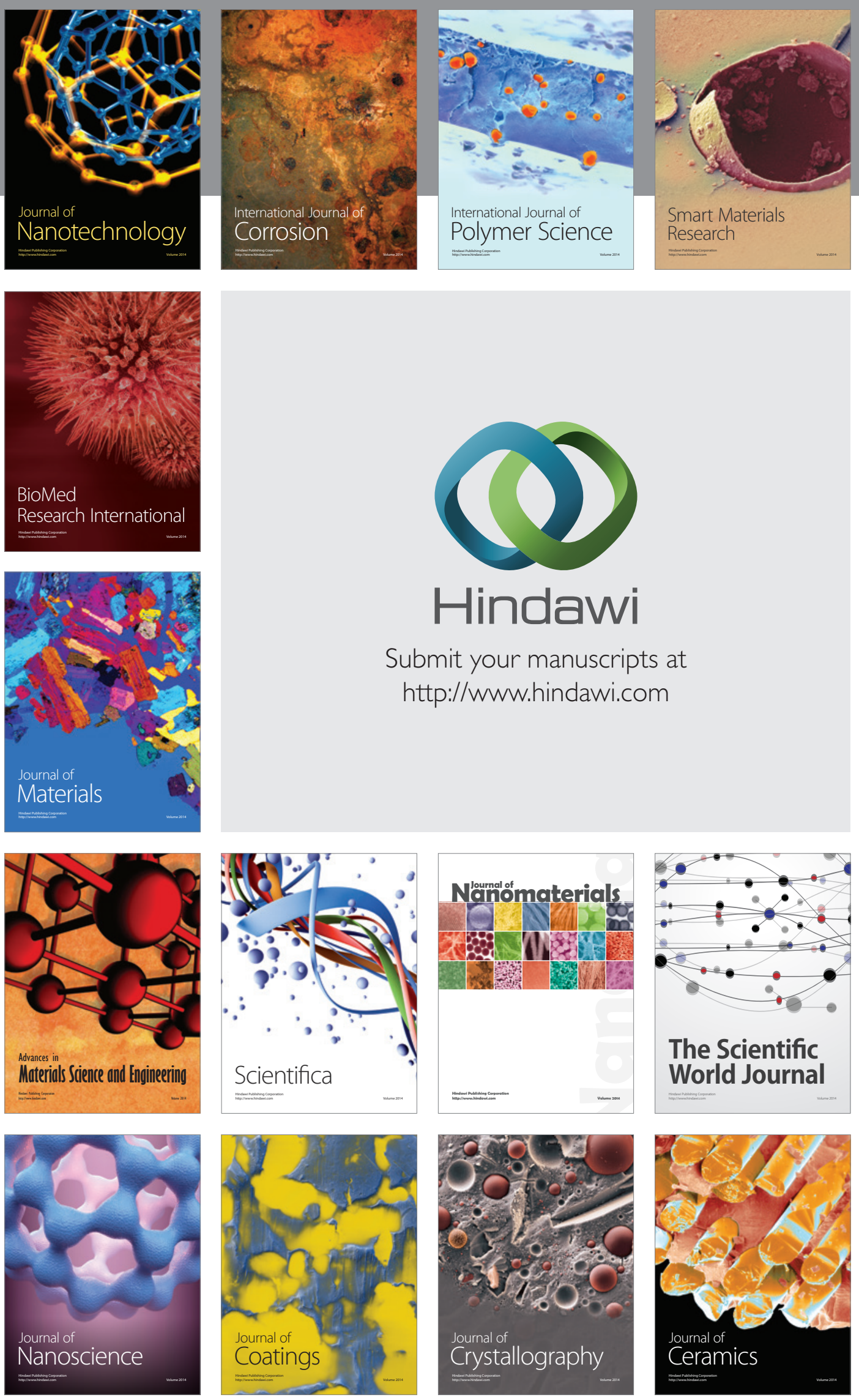

The Scientific World Journal

Submit your manuscripts at

http://www.hindawi.com

\section{World Journal}

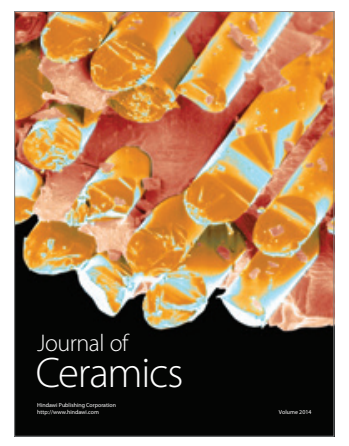

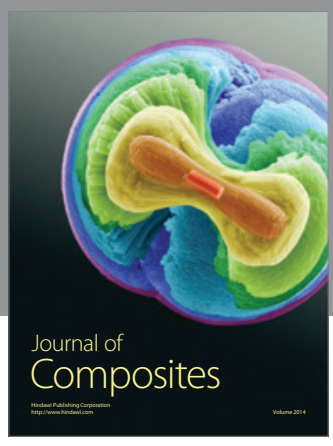
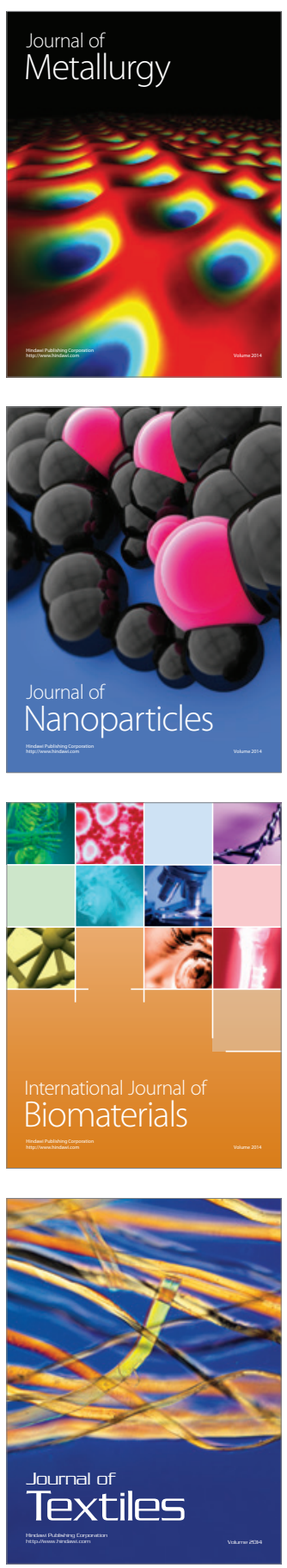